Article

\title{
Assessment of WorldView-3 Data for Lithological Mapping
}

\author{
Bei Ye ${ }^{1}$, Shufang Tian ${ }^{1}$ *, Jia Ge $^{2}$ and Yaqin Sun ${ }^{3}$ \\ 1 School of Earth Sciences and Resources, China University of Geosciences (Beijing), Beijing 100083, China; \\ yebei_1123@163.com \\ 2 Oil and Gas Survey, China Geological Survey, Beijing 100083, China; gejiaaa@gmail.com \\ 3 China Aero Geophysical Survey and Remote Sensing Center (AGRS), Beijing 100083, China; \\ sun_yaya@126.com \\ * Correspondence: sftian@cugb.edu.cn; Tel.: +86-010-8232-2163
}

Received: 13 September 2017; Accepted: 2 November 2017; Published: 6 November 2017

\begin{abstract}
The WorldView-3 (WV-3) satellite is a new sensor with high spectral resolution, which equips eight multispectral bands in the visible and near-infrared (VNIR) and additional eight bands in the shortwave infrared (SWIR). In order to meet the requirements of large-scale geological mapping, this paper assessed WV-3 data for lithological mapping in comparison with Advanced Spaceborne Thermal Emission and Reflection Radiometer (ASTER) and Operational Land Imager (OLI/Landsat-8) data. The study area is located in the Pobei area of the Xinjiang Uygur Autonomous Region, where bedrock outcrops are widely distributed. The whole experiment was divided into six steps: data pre-processing, visual interpretation of various lithological units, samples procedure, lithological mapping by a support vector machine algorithm (SVM), accuracy evaluation, and assessment. The results showed that the classification accuracy of WV-3 data was $87 \%$, which kept $17 \%$ higher than that of ASTER data, 14\% higher than that of OLI/Landsat-8 data, indicated that WV-3 data contained more diagnostic absorption features mainly thanks to its SWIR bands, and benefited by its high spatial resolution, as well. However, it also confirmed that there were some considerable flaws, such as the confusing identification of biotite-quartz schist. Overall, the WV-3 data is still the most promising data for geological applications currently.
\end{abstract}

Keywords: WorldView-3; lithological mapping; spectral and spatial assessment; SVM algorithm

\section{Introduction}

Moderate-resolution remote sensing multispectral data, such as Thematic Mapper (TM), Enhanced Thematic Mapper Plus (ETM+), Operational Land Imager (OLI), and Advanced Spaceborne Thermal Emission and Reflection Radiometer (ASTER) data, have been applied to alteration information extraction, fracture structure interpretation, lithological identification, etc., which have played a significant role in the regional geological survey and mineral exploration. ASTER data has been particularly widely used thanks to its shortwave infrared (SWIR) and thermal infrared (TIR) bands, which could provide diagnostic absorption features for some special minerals [1-7]. ETM+ and OLI data have often been applied since these data cover the range of spectra from visible to shortwave infrared and could be easily obtained [8-10]. Several case studies have demonstrated the merit of remote sensing data for direct lithological mapping. For instance, extracting multiple feature layers from a single data source and applying various excellent classifiers has been a common and effective method to improve the classification accuracy. Masoumi et al. [11] integrated spectral, thermal, and textural features of ASTER data using random forest classification for lithological mapping, achieved a higher accuracy (approximately 80\%), and machine learning algorithms have been used frequently, especially support vector machines (SVMs). There have been a number of successful 
applications [12-17], which have verified two crucial viewpoints: firstly, SVM models are applicable to various data or their combination; secondly, SVM classification results tend to be better than other commonly-used methods due to its excellent detailed describing capability of information.

However, these satellite platforms have been limited by their coarse spatial and spectral resolution. Due to the existence of numerous mixed pixels in medium-resolution data, the spectral and structural information could not satisfy the more complex lithological information extraction, and the lithological classification accuracy remained low. With the occurrence of high-resolution data, like SPOT, Quickbird, and GF-2, the problem of low classification accuracy was alleviated, to some extent. But these data have been often used solely in visual interpretation [18]. High-resolution data have outstanding capacity of structure and texture features, but the spectral range of these high-resolution satellite data is relatively narrow, consisting of only four bands, covering visible to near-infrared spectrum (approximately 450-1040 nm), and lacking shortwave infrared wavelength data. Thus predecessors have used some technical methods to cooperatively manage different types of data, compensating for the deficiency that application of a single data source in the lithological identification and classification was not sufficient [19-22]. However, the technology has only brought some minor improvements, while it truly faces the loss during the integration of various data and the increasing cost of data acquisition. Additionally, the ASTER SWIR detectors were no longer operating and the data were not applicable since April 2008. Meanwhile, some other types of data have been used in lithological mapping, such as Airborne hyperspectral thermal infrared data, Phased Array type L-band Synthetic Aperture Radar (PALSAR) data, Light Detection And Ranging (LiDAR) data and so on. Black et al. [23] presented a new fully-automated processing chain for deriving lithological maps from hyperspectral thermal infrared data; Deroin et al. [24]carried out a quantitative approach in order to estimate the backscatter properties of the main rock types. It was stated that due to the large variety of configurations, radar satellite imagery such as PALSAR represented a key tool for geological mapping in arid region at different scales. And PALSAR data was broadly applicable for structural geology and topographic mapping [25,26]; Grebby et al. [27] assessed the efficacy of airborne LiDAR as a tool for detailed lithological mapping and an artificial neural network was employed to classify the lithological units. The results demonstrated the significant potential of airborne LiDAR for lithological discrimination and rapid generation of detailed lithological maps, as a contribution to conventional geological mapping programs. However, acquisition cost and the practicability are the two key issues that we must consider carefully when selecting data. Therefore, it is vital to seek an accessible and effective remote sensing data source.

The successful launch of the WorldView-3 (WV-3) satellite by Digital Globe on 13 August 2014 has opened up new opportunities to map mineral assemblages, vegetation cover, and man-made materials with greater spatial and spectral resolution [28]. In recent years, there have been some studies on WV-3 or simulated WV-3 data. For example, it was demonstrated that hydrocarbon absorption feature in WV-3's band 12, accompanied by shoulders sustained at bands 11 and 13 (centered at 1660 and $2165 \mathrm{~nm}$ ), was resilient enough and persisted under various conditions. Thus, a simple index, just like (b11 + b13)/b12, could unambiguously highlight the presence of hydrocarbons in one pixel, which has great significance for the detection of subtle oil leakage [29]. WorldView-3's SWIR bands are excellent for alteration information extraction, as well as hydrocarbon detection. Kruse [28] and Yaqin Sun et al. [30] also suggested that, thanks to the SWIR bands, the WV-3 data had very good performance in extracting hydroxyl-bearing alteration, and it was suited for iron-bearing and carbonate-bearing alteration, as well. Note that a band set of WV-3 data near 1200 nm was very effective for extracting $\mathrm{Fe}^{2+}$-bearing alterations. Other research focuses on georeferencing accuracy analysis, topographical surface feature classification and monitoring, or accuracy evaluation on WV-3' derivatives [31-37]. The above studies indicated the WV-3 data in both information extraction and feature classification had great application potential. However, until now, there is little literature on research or application about lithological identification and mapping using WV-3 data. 
Therefore, this article has two purposes: (1) to assess the suitability of WV-3 data for lithological mapping; and (2) to perform a detailed comparison of different data types for lithological classification with ASTER and OLI/Landsat-8 data in our study area.

\section{Study Area}

The study area is located in the Pobei area of the Xinjiang Uygur Autonomous Region, China. The area is about $12 \mathrm{~km}^{2}$, which belongs to the low mountain-hilly terrain, and the average elevation is about $1286 \mathrm{~m}$. The region is sparsely populated with large-area exposure of the bedrock. Additionally, the research area is located in the central Asian orogenic belt, the western area of the northern mountain rift valley, the east side of Lop Nur, where a large amount of magmatite is exposed, and comprises some strata as well (Figure 1).

According to regional geological background material, because of the complex geological evolution, intense tectonic movements, and frequent magmatic activities, the intrusive rocks are considered to have multi-time and multi-type characteristics, which are significant as they record variations in melting depths and the stress regime in the lithosphere. The magmatic rocks in the study area are mainly Variscan diorite, with little gneissic neutral-acid intrusive rocks, granite, and gabbro. The exposed strata consist of Paleozoic carboniferous Hongliuyuan strata (C1h) and Mesoproterozoic Gudongjing terrain (ChG). Mesoproterozoic Gudongjing terrain is a set of schist, comprising upper and lower parts. The lower lithology consists of biotite-quartz schist and two-mica quartz schist, the upper part contains biotite schist and biotite-quartz schist. Mesoproterozoic Gudonging terrain produces schistosity because of metamorphism, with some metamorphic minerals directionally arranging, such as biotite, epidote, chlorite, actinolite, and andalusite. Paleozoic carboniferous Hongliuyuan strata $(\mathrm{C} 1 \mathrm{~h})$ are terrigenous clastic rock, being mingled with carbonatite, pyroclastic rock, and volcanic lava. Most of them underwent ductile shear deformation and metamorphosis [30].

In the geological history, a complex fracture system in different directions has formed, which are the two main groups of faulted structures, northeast and northwest, as shown in the Figure $1 \mathrm{~b}$. The fracture tectonics were generally accompanied by a strong and physicochemical lithological action, which formed the corresponding foliation zone and the mylonitic lithologic belt, showing the obvious characteristics of toughness deformation and forming a strong strain region.
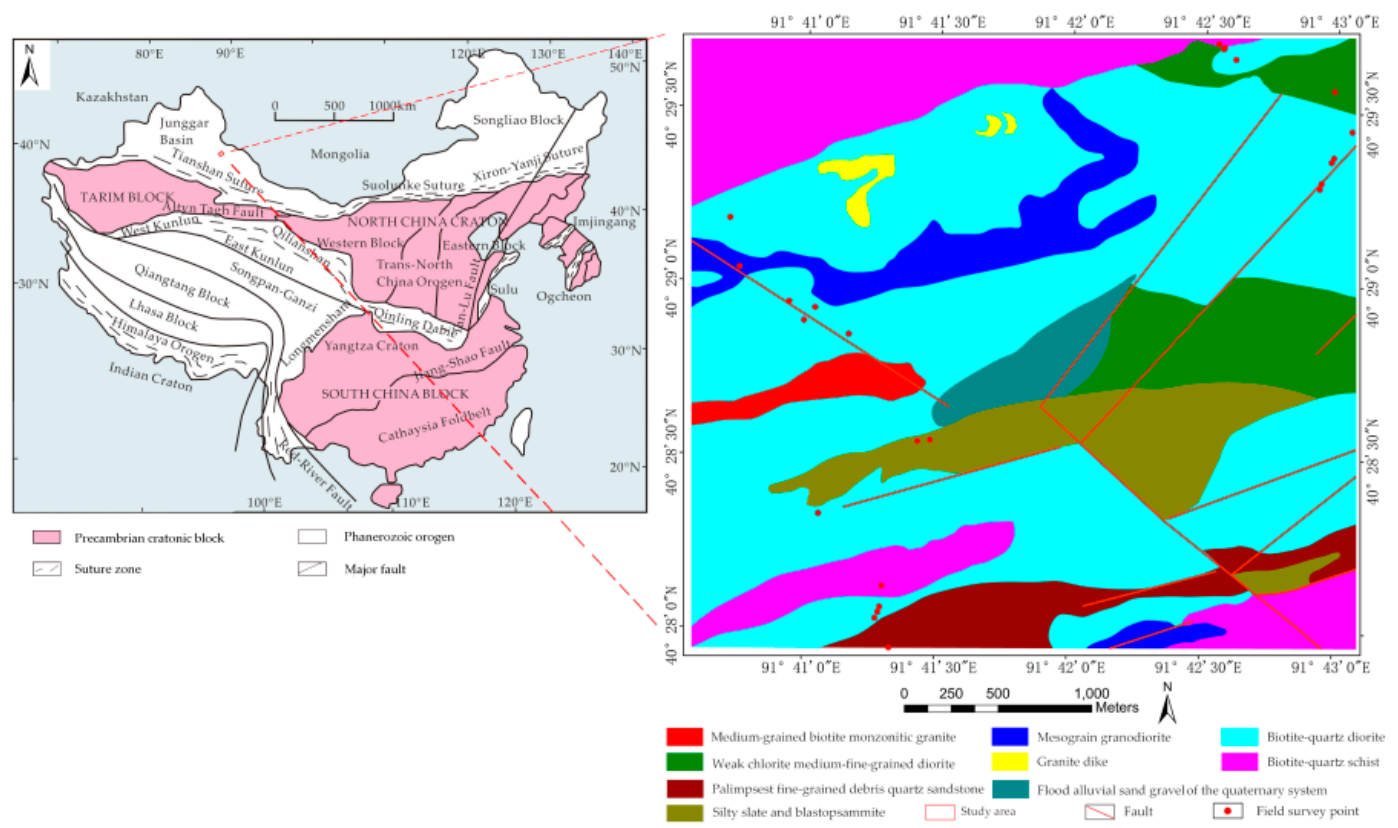

(a)

Figure 1. Cont. 


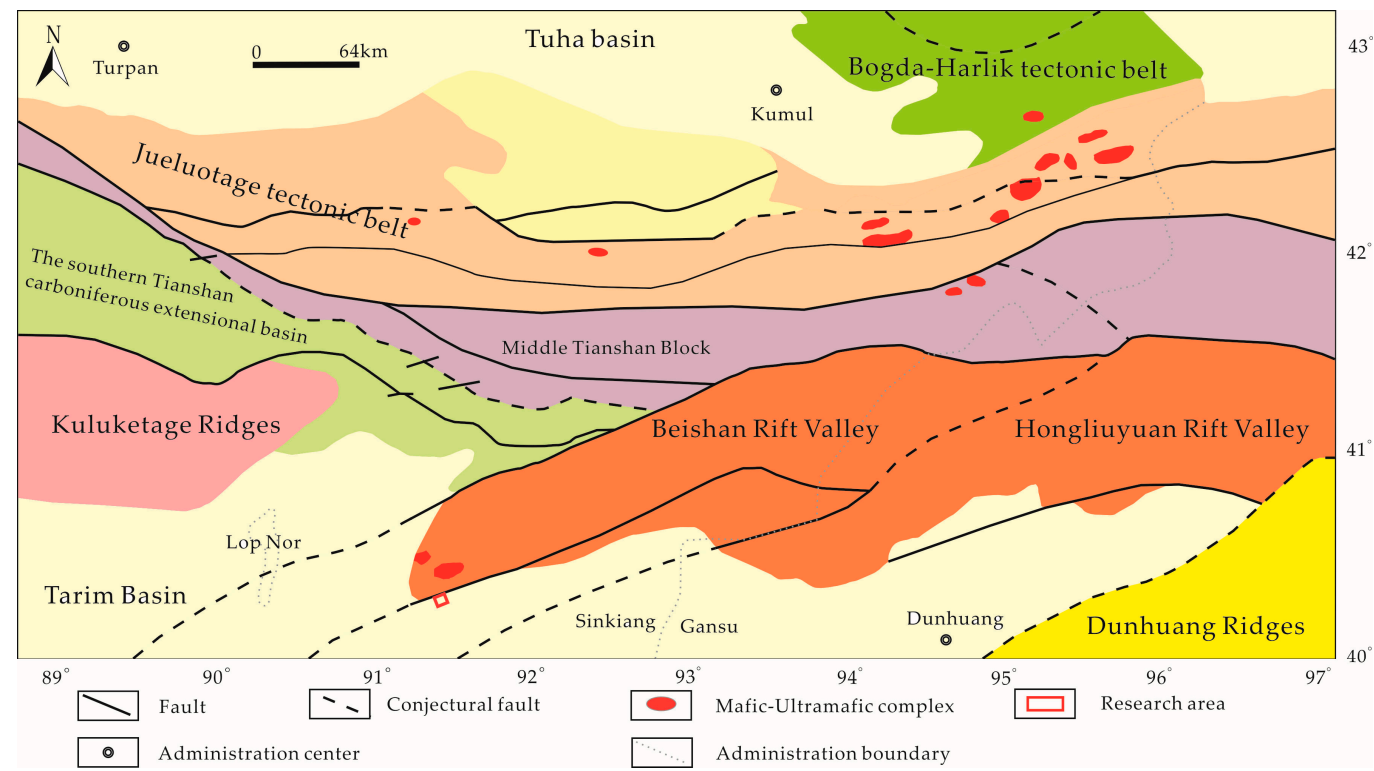

(b)

Figure 1. (a) Simplified tectonic map of China showing major cratonic blocks and orogenic belts, the location of study area is labeled (modified after Zheng et al. [38]). And a schematic geologic map of the study area is shown on the right (modified after a geological map at a scale of 1:100,000 which created in 2015 and Sun et al. [30]). Field survey points are shown in the schematic geologic map and field survey would be introduced in Section 3.1; and (b) regional tectonic map (modified after Su et al. [39]).

\section{Materials and Methods}

\subsection{Data Sources}

The data sources involved in this article included remote sensing data, regional geological material and ground survey data. Remote sensing data consisted of WorldView-3, ASTER and OLI/Landsat-8 data.

WorldView-3 is the first multi-payload, super-spectral, high-resolution commercial satellite sensor operating at an altitude of $617 \mathrm{~km}$, which includes the standard panchromatic and multispectral bands, eight-band shortwave infrared (SWIR), and twelve CAVIS imageries (Table 1). The WorldView-3 satellite provides $31 \mathrm{~cm}$ panchromatic resolution, $1.24 \mathrm{~m}$ multispectral resolution, $3.7 \mathrm{~m}$ shortwave infrared resolution, and $30 \mathrm{~m}$ CAVIS resolution. The satellite has an average revisit time of less than one day and is capable of collecting up to $680,000 \mathrm{~km}^{2}$ per day [40]. In the visible and near-infrared, WorldView-3 provides four standard color bands (blue, green, red, and near-IR1) and four another additional bands (coastal, yellow, red edge, and near-IR2), bearing a strong resemblance to its predecessor WorldView-2.

Table 1. Characteristics and wavelength ranges of WorldView-3 (source: Digital Globe [41]).

\begin{tabular}{cccccccc}
\hline Sub-System & $\begin{array}{c}\text { Band } \\
\text { Number }\end{array}$ & $\begin{array}{c}\text { Band } \\
\text { Name }\end{array}$ & $\begin{array}{c}\text { Wavelength } \\
\text { Range }(\mathbf{n m})\end{array}$ & Sub-System & $\begin{array}{c}\text { Band } \\
\text { Number }\end{array}$ & $\begin{array}{c}\text { Band } \\
\text { Name }\end{array}$ & $\begin{array}{c}\text { Wavelength } \\
\text { Range (nm) }\end{array}$ \\
\hline \multirow{6}{*}{ VNIR } & 1 & Coastal & $400-450$ & & 9 & SWIR1 & $1195-1225$ \\
& 2 & Blue & $450-510$ & & 10 & SWIR2 & $1550-1590$ \\
& 3 & Green & $510-580$ & & 11 & SWIR3 & $1640-1680$ \\
& 4 & Yellow & $585-625$ & SWIR & 12 & SWIR4 & $1710-1750$ \\
& 5 & Red & $630-690$ & & 13 & SWIR5 & $2145-2185$ \\
& 6 & Red edge & $705-745$ & & 14 & SWIR6 & $2185-2225$ \\
& 7 & Near-IR1 & $770-895$ & & 15 & SWIR7 & $2235-2285$ \\
& 8 & Near-IR2 & $860-1040$ & & 16 & SWIR8 & $2295-2365$ \\
\hline
\end{tabular}


ASTER and OLI/Landsat-8 data are most commonly used in geological application. In comparison with ASTER and OLI/Landsat-8 data, the full strengths of WV-3 data are highlighted (Figure 2). In the visible and near-infrared, WV-3 completely covers both of them with several additional bands. WV-3 data divides into four SWIR bands in 1195-1750 nm regions relative to one single band in both ASTER and Landsat-8 instruments. WV-3's SWIR 5-8 are approximately identical to ASTER's SWIR 2-5, which wavelength extends from $2145 \mathrm{~nm}$ to $2365 \mathrm{~nm}$, overlap with OLI/Landsat-8's SWIR2 as well. However, ASTER's SWIR6 (spanning between 2360 and 2430) is lacking in either WV-3 or OLI/Landsat-8 data. In general, WV-3 data seems to possess great potential for gathering information. As for the application of lithological mapping, it is worth investigating.

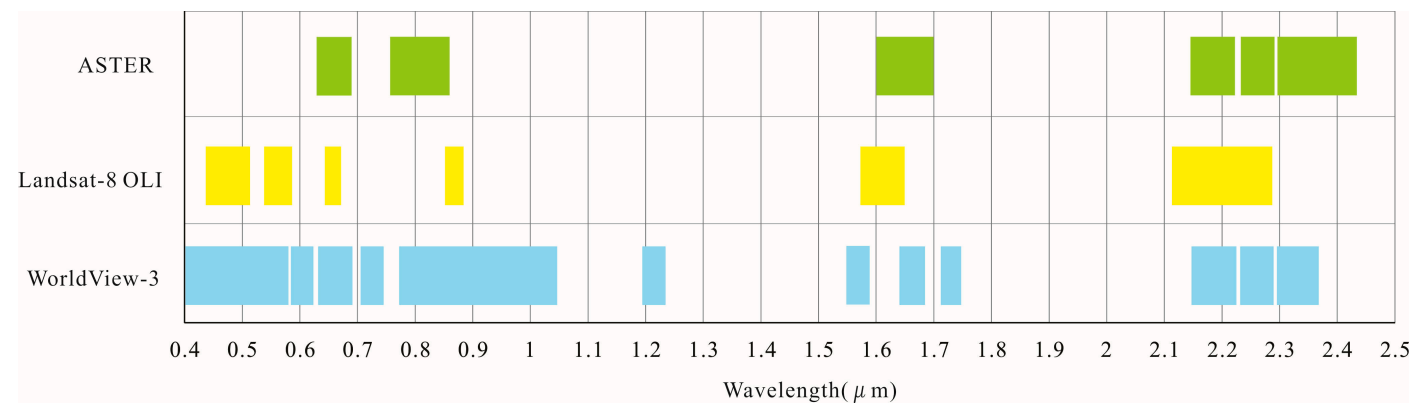

Figure 2. Bands comparison of WorldView-3, ASTER and OLI/Landsat-8 data in VNIR and SWIR spectral range. The spectrum of the WV-3 data is relatively broad.

The VNIR and SWIR bands of WorldView-3, ASTER, and OLI/Landsat-8 data were adopted in this paper. The WorldView-3 data was obtained from Siwei WorldView Technology Company (Beijing, China), at the level L2A. VNIR data were acquired at 14:00 pm, 2 May 2015, while the SWIR data was at 14:00 pm, 1 May 2015. The WV-3 data provided $2 \mathrm{~m}$ multispectral resolution and $7.5 \mathrm{~m}$ short-wave infrared resolution which were resampled from $1.24 \mathrm{~m}$ and $3.7 \mathrm{~m}$ respectively due to commercial restriction. The level 2A data already had a systematic radiometric calibration and geometric correction and were pre-georeferenced to UTM zone 46 North projection using the WGS-84 datum. The ASTER data acquired on 13 May 2002, at the level L1B, and OLI/Landsat-8 data acquired on 31 July 2013, at the level L1T had the same coordinate system as the WV-3 data. It is important to note that due to data source constraints, the ASTER and WV-3 image differed greatly in the time phase. There were three main reasons for choosing the data though the dates of acquisition were greatly different: first, the ASTER SWIR data has always been an outstanding contribution in lithological mapping application, and additional eight bands in the shortwave infrared of WV-3 data were worthy of special attention and in-depth study. So comparative analysis with ASTER data was meaningful and necessary; second, in the previous studies, a variety of data were integrated for lithological mapping and there were large difference in data acquisition time, but the results showed that the errors caused by the phase difference were not obvious. For example, there was a difference of 10 years between ASTER image and OLI/Landsat-8 image for lithological mapping in the Bas Drâa inlier, Moroccan Anti Atlas [19]; and cloud free Landsat TM image data acquired on 21 October 2010 and ASTER Level $1 \mathrm{~B}$ image data acquired on 30 August 2003 for chromite prospecting and lithological mapping study in Neyriz ophiolite zone, south Iran [20]; third, the ASTER SWIR detectors were no longer operating and the data were not applicable since April 2008. And the ASTER data used in this article was one of the best data that could be obtained after eliminating various factors. Therefore, despite the inevitable errors, we still hoped to assess the application potential of WV-3 data for lithological mapping from more perspective by comparing with ASTER data.

Regional geological material and ground survey data were provided by China Aero Geophysical Survey and Remote Sensing Center (AGRS). Regional geological material included a geological map at a scale of 1:100,000 and relevant documentation, created in 2015. Ground survey data were acquired 
in July 2015. There were 25 lithological observation points which were not evenly distributed due to the traffic restrictions (Figure 1a). Actual spectral curves of 50 lithological samples were measured by Analytical Spectral Devices (ASD) Field spec-FRTM spectroradiometer.

\subsection{Pre-Processing of Remote Sensing Data}

Pre-processing of WV-3 data was divided into three steps as follows:

(1) Radiometric calibration. The digital numbers (DN) in the pixel of the original image were 16-bit integers. Radiometric calibration converted the data of the observed surface into physical radiance; and

(2) Atmospheric correction. While the wavelength range is an atmospheric window, there is atmospheric influence, including scattering, absorbing, attenuating energy, or changing the spectral distribution, which needs to be compensated for, especially for quantitative applications. Previous studies have shown that the Fast Line-of-sight Atmospheric Analysis of Spectral Hypercubus module (FLAASH module) is valid for both hyper-spectral and multi-spectral imagery, which has a better utility and practicability [42,43]. Meanwhile, Nisha Rani et al. [44] recommended that FLAASH was better than Quick Atmospheric Correction (QUAC) for atmospheric correction and correct interpretation and identification of composition of any object or minerals. Therefore, WV-3 bands were corrected by the FLAASH module.

(3) Geometric correction, data resampling and stacking. Since VNIR and SWIR data acquisition time were different, there was geographical deviation between the two kinds of data. Based on VNIR data, the SWIR data was calibrated and the total RMS error was controlled within one pixel. Simultaneously, SWIR bands were resampled to $2.0 \mathrm{~m}$ and stacked with the VNIR bands, in order to centralize the multispectral features into one single file.

Pre-processing of ASTER data mainly includes removing crosstalk effects, resampling and stacking, radiometric calibration and atmospheric correction. The crosstalk software provided by Earth Remote Sensing Data Analysis Center (ERSDAC) was used for correcting the SWIR bands' crosstalk effects. The elimination of the effects of energy overspill from Band 4 into Bands 5 and 9 was realized by crosstalk correction $[45,46]$. The ASTER SWIR data with $30 \mathrm{~m}$ spatial resolution were resampled at $15 \mathrm{~m}$ to fit with VNIR data applying a bilinear method. Thus, the VNIR and SWIR bands were combined to form nine bands at $15 \mathrm{~m}$ spatial resolution. Afterwards, radiometric calibration and atmospheric correction was executed. Additionally, 3B and TIR bands did not participate the pre-processing.

Pre-processing of OLI/Landsat-8 data was comparatively mature, mainly containing radiometric calibration and atmospheric correction. The operation involved seven bands of multispectral (Bands 1-7). In order to keep the same spatial resolution with ASTER image, the Gram-Schimidt spectral shaping method was adopted to realize image fusion with the pan-spectral image and multispectral image of OLI/Landsat-8 data.

Note that the same radiometric calibration module and FLAASH module were used to reduce the error between the various data caused by pre-processing operations.

After pre-processing, these three kinds of data should be strictly spatially matched, using the WV-3 image as a spatial reference. Then, the subset of three kinds of images with the study area vector file and the visual effect of the three images was better after pre-processing.

\subsection{Visual Interpretation of Lithological Units}

Due to the randomness and fuzziness of the spectral features, the "same object with different spectra" or "different object with same spectra" phenomenon is widespread. Therefore, visual interpretation has still been one of the most effective methods for the lithological mapping until now. Thus, a local-scale geological map of the study area, based on the previous geological map (Figure 1a) updated with recent field investigation and WV-3 data by visual interpretation. 


\subsection{Samples Procedure}

A lithological map is the result based on the spectral information contained in each pixel. Before the samples procedure, the normalized difference vegetation index (NDVI) was calculated. And the NDVI was used to indicate vegetation cover in the study area. The mean of NDVI was less than 0.06 , which proved that the vegetation coverage in the study area was very low and the bedrock was well exposed. Thus vegetation had little effect on this study.

Minimum noise fraction (MNF), pixel purity index (PPI), and the $\mathrm{N}$-dimensional visualization tool were used for the collection of endmembers based on three remote sensing images $[47,48]$. And Training samples were extracted from these endmembers according to the lithological map of visual interpretation. In order to avoid underfitting, the number of samples in each category should be larger than the total number of classifications. The training samples should be distributed evenly throughout the study area and avoid the boundary of different lithological units. After the selection of training samples, the separability of the samples was calculated, which was represented by the Jeffries-Matusita, transformed divergence parameter. Besides, the three sets of training samples should be kept as close as possible in space and be consistent in the sample size.

Test samples were selected randomly and evenly throughout the whole study area according to the lithological map of visual interpretation. And the test samples were totally different from the training samples.

\subsection{Lithological Mapping by Support Vector Machine}

In machine learning, support vector machines (SVMs) are supervised learning models with associated learning algorithms that analyze data used for classification and regression analysis. Given a set of training examples, each marked as belonging to one or the other of two categories, an SVM training algorithm builds a model that assigns new examples to one category or the other, making it a non-probabilistic binary linear classifier [49]. In application, SVMs can be generalized from dichotomies to multiple categories. Research showed that SVMs have better adaptability and promotion ability than traditional methods (including neural network) in lithological mapping application [50-52]. An important advantage of SVM models is the description of the complexity, which can be characterized by the number of support vectors rather than the dimensions of the transformation space. Hence, SVM models are usually less likely to be overfitted as other methods. Simultaneously, SVM models are not affected by the "dimension disaster" and are suitable for the extraction of comprehensive information of high-dimensional remote sensing data [17]. When referring to classification based on remote sensing data using SVMs, it does not usually mean linear SVM, but the nonlinear separable SVMs, which require a nonlinear kernel function to map the classified data set to a higher dimensional feature space for linear hyperplane.

The radial basis function (RBF) is widely used in remote sensing applications, and its parameters determine the shape of this high-dimensional mapping, which directly affects the classification accuracy [53]. It can be seen that the performance of SVMs is determined largely by the penalty coefficient (C) and the parameters of the kernel function. The concept and advantages of SVMs are introduced here briefly, and the detailed algorithm of the SVM can refer to the literature and books on machine learning $[54,55]$. Therefore, this paper executed lithological mapping by an SVM model, which often yields good classification results from complex and noisy data.

The SVM model was trained according to the training samples. SVM models require importing the kernel type, and the gamma in the kernel function, and a penalty parameter. This article chose the radial basis function as the kernel type. The gamma in the kernel function is adopted to set the gamma parameter used in the kernel function, which is a floating point value greater than 0 . The default is the inverse of the number of bands in the input image. The penalty parameter controls the trade-off between allowing training errors and forcing rigid margins. Increasing the value of the penalty parameter increases the cost of misclassifying points and creates a more accurate model that may not generalize well. In order to manifest the real spectral capability of three kinds of data, 
the same number training samples, test samples, and kernel type were used during the classification process of different data. Other parameters of the SVM model adopted default values.

In the application of classification using remote sensing images, it is inevitable to produce some fragmentary speckles. Therefore, it is necessary to remove and reclassify these speckles from the viewpoint of thematic drawing or practical application. The classification results were treated by means of majority filtering analysis, and the speckles were merged into the surrounding pattern spots. After trial and error, a five-by-five filter window for the lithological map of WV-3 data was determined and three-by-three filter windows were adopted for the classification results of ASTER and OLI/Landsat-8 images.

\subsection{Accuracy Evaluation}

The classification accuracy was quantitatively evaluated by test samples via a confusion matrix, and the kappa coefficient. And the Overall, User's and Producer's accuracies were defined for testing the classification accuracy [56]. The overall accuracy is the radio between all validation pixels correctly classified (the total correct pixels) and validation pixels (the total number of pixels in the error matrix), whereas the user's accuracy includes commission errors and the producer's accuracy includes omission errors related to the individual classes $[15,57,58]$. The kappa coefficient is a statistical measure of agreement taking into accounts all of the categories. It has a value close to zero when the observed agreement is the same as expected by chance and a value approaching one with perfect agreement [59]. And the test samples were selected randomly according to the lithological map of visual interpretation.

\section{Results}

\subsection{Lithological Map of Viaual Interpretation}

A local-scale geological map of the study area, based on previous geological maps updated with WV-3 data and field investigation data, is shown in Figure 3.

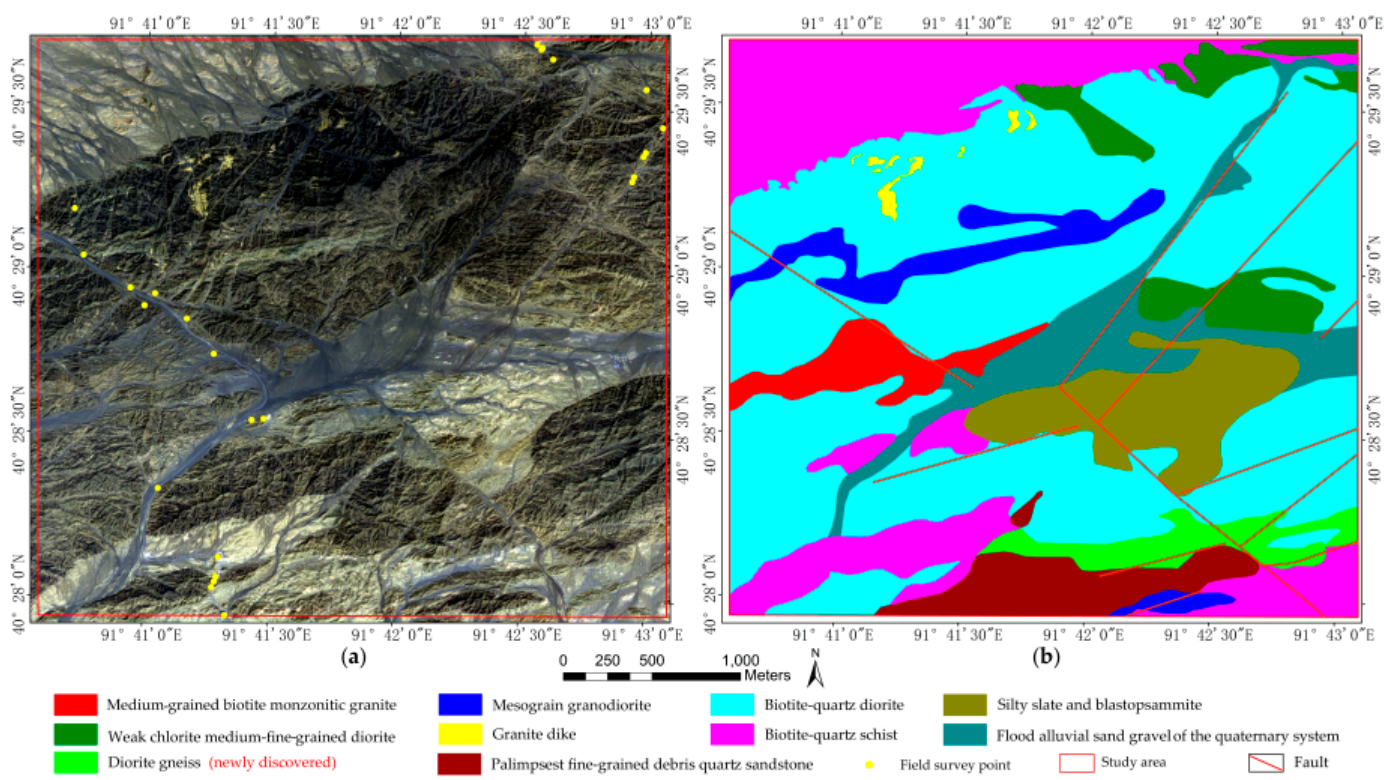

Figure 3. (a) Field survey points distribution map in WorldView-3 image (R: Band 8, G: Band 5, B: Band 1). These points were not evenly distributed due to the traffic restrictions, and the ground survey data were acquired in July 2015; and (b) the lithological map of visual interpretation. This geological map of the study area was based on the previous geological map and updated with the field investigation data and WV-3 data as shown in Figure 3a. 
Results showed that the study area could be divided into 10 types of lithological units, medium-grained biotite monzonitic granite, weak chlorite medium-fine-grained diorite, mesograin granodiorite, granite dike, biotite-quartz diorite, biotite-quartz schist, silty slate and blastopsammite, flood alluvial sand gravel, palimpsest fine-grained debris quartz sandstone, and diorite gneiss, respectively. As can be seen from Figure 3b, most of the research area was covered with diorite.

In the process of visual interpretation, a strip of land was newly discovered comparing with Figure 1a, which was significantly different from the surrounding strata in WV-3 SWIR image, but there was no real difference in WV-3 VNIR image (Figure 4). According to the data of field survey and the comparison with the Johns Hopkins University (JHU) spectral library provided by Environment for Visualizing Images (ENVI) software, it was determined as diorite gneiss. Meanwhile, it could be seen from Figures $1 \mathrm{a}$ and $3 \mathrm{~b}$ that the distributions of lithological units were about the same, but there were some differences between the distribution shapes and the size of each unit, which was mainly caused by the difference in cartographic scale. Besides, note that the previous lithological map was not always accurate reflection of the surface and subsurface conditions, and there were some projections of cartographers and smooth treatment of the contact boundary.

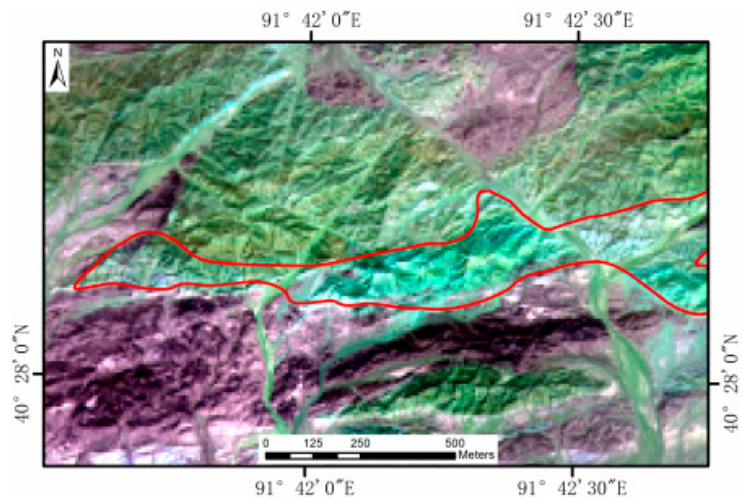

(a)

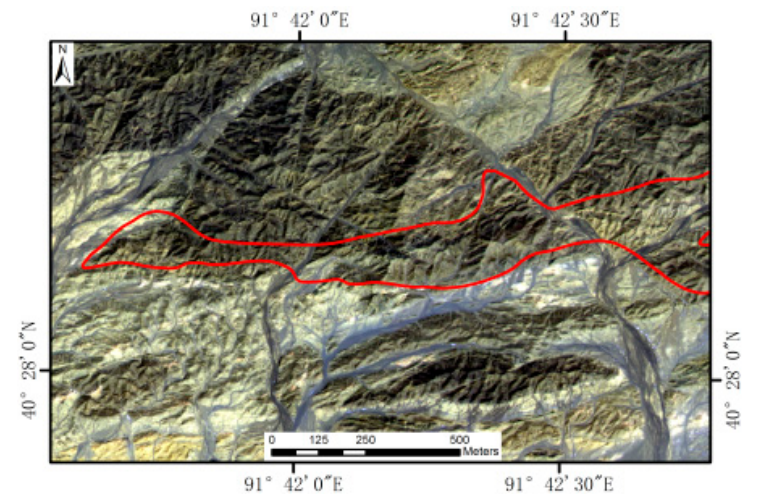

(b)

Figure 4. The area delineated by red line was a newly discovered lithological unit. (a) The newly discovered lithological unit in WV-3 SWIR image before resampling (R: Band 16, G: Band 13, B: Band 11); and (b) the newly discovered lithological unit in WV-3 VNIR image (R: Band 8, G: Band 5, B: Band 1). The figure showed that the newly discovered lithological unit expressed dark green in WV-3 SWIR image, which was a different hue with the surrounding, while there was no notable distinction in WV-3 VNIR image. The red line was outlined by visual interpretation.

\subsection{Training and Test Samples}

We carefully selected training and test samples corresponding to ten lithological units. 103 regions of interest were selected as training samples, each of which included nine pixels, for a total of 927 training samples. And the separability of the three sets of samples was calculated, the results showed that the minimum value was 1.93 , which was greater than 1.90 , indicated that the samples were separable and belonged to the qualified samples. Another 103 regions of interest were selected as test samples, each of which included nine pixels, and 927 test samples were selected randomly and evenly throughout the whole study area. Three sets of samples of three remote sensing data kept consistent in sample size and the sample data distribution is shown in Table 2. Since the coverage of biotite-quartz diorite was the widest, the sample size was larger. 
Table 2. Sample data statistics.

\begin{tabular}{cccc}
\hline \multirow{2}{*}{ Category Number } & Category Name & \multicolumn{2}{c}{ Sample Size (Pixel) } \\
\cline { 3 - 4 } & Training Samples & Test Samples \\
\hline 1 & Medium-grained biotite monzonitic granite & 90 & 90 \\
2 & Weak chlorite medium-fine-grained diorite & 90 & 90 \\
3 & Mesograin granodiorite & 90 & 90 \\
4 & Granite dike & 90 & 90 \\
5 & Biotite-quartz diorite & 117 & 90 \\
6 & Biotite-quartz schist & 90 & 90 \\
7 & Silty slate and blastopsammite & 90 & 90 \\
8 & Flood alluvial sand gravel & 90 & 90 \\
9 & Palimpsest fine-grained debris quartz sandstone & 90 & 90 \\
10 & Diorite gneiss & 927 & 927 \\
\hline
\end{tabular}

\subsection{Lithological Classification Maps}

Lithological classification map of WV-3 data after the post-classification processing is shown in Figure 5. More details were available in the classification result of WV-3 data. From the perspective of overall visual effect, WV-3's lithological classification map was more similar to the geological map of visual interpretation (Figure 3b). Ten lithological units were well distinguished.

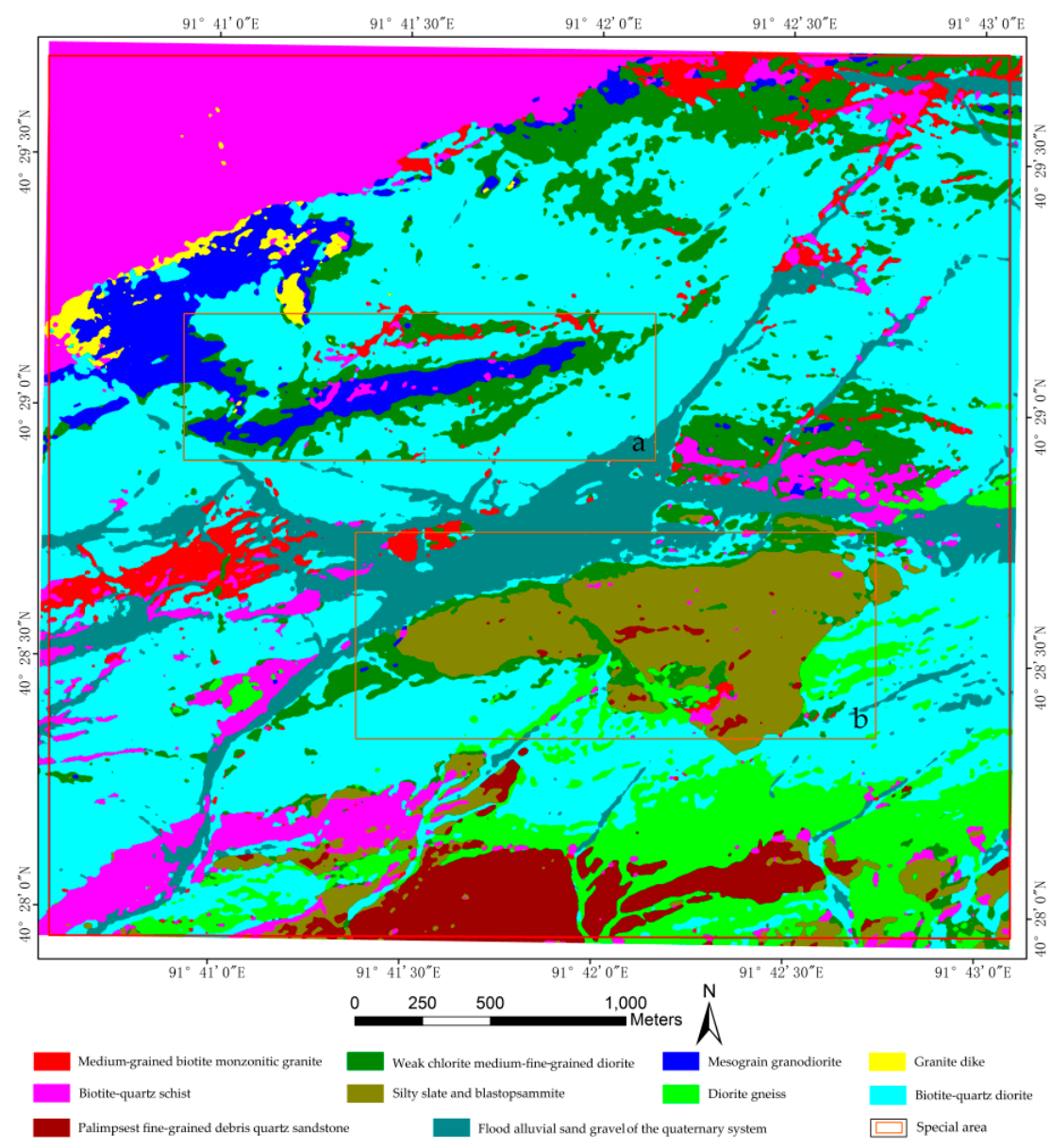

Figure 5. Lithological classification map of WV-3 data after the post-classification processing. (a) Mesograin granodiorite was surrounded by weak chlorite medium-fine-grained diorite, and it was connected with biotite-quartz diorite; and (b) weak chloritization and diorite gneiss distributed around a fault. 
By comparing with the geological map of visual interpretation (Figure 3b), two interesting phenomena were found in the WV-3 lithological classification map: firstly, mesograin granodiorite was surrounded by weak chlorite medium-fine-grained diorite, and it was connected with biotite-quartz diorite, which revealed the special rock mass activity in a certain extent. However, speculating the process of regional geological evolution according to the classification results is not rigorous enough, so a large number of field investigation and theoretical verification are needed; second, the weak chloritization and diorite gneiss were well detected around the fracture and closely related to the fracture activity.

Lithological classification maps of ASTER and OLI/Landsat-8 data after the post-classification processing are shown in Figure 6. These lithological units were roughly similar across the three lithological maps created by SVM, but there were some differences in the details. Therefore, we calculated the area percentage of various lithological units of three lithological classification maps in order to reveal their differences clearly (Table 3).

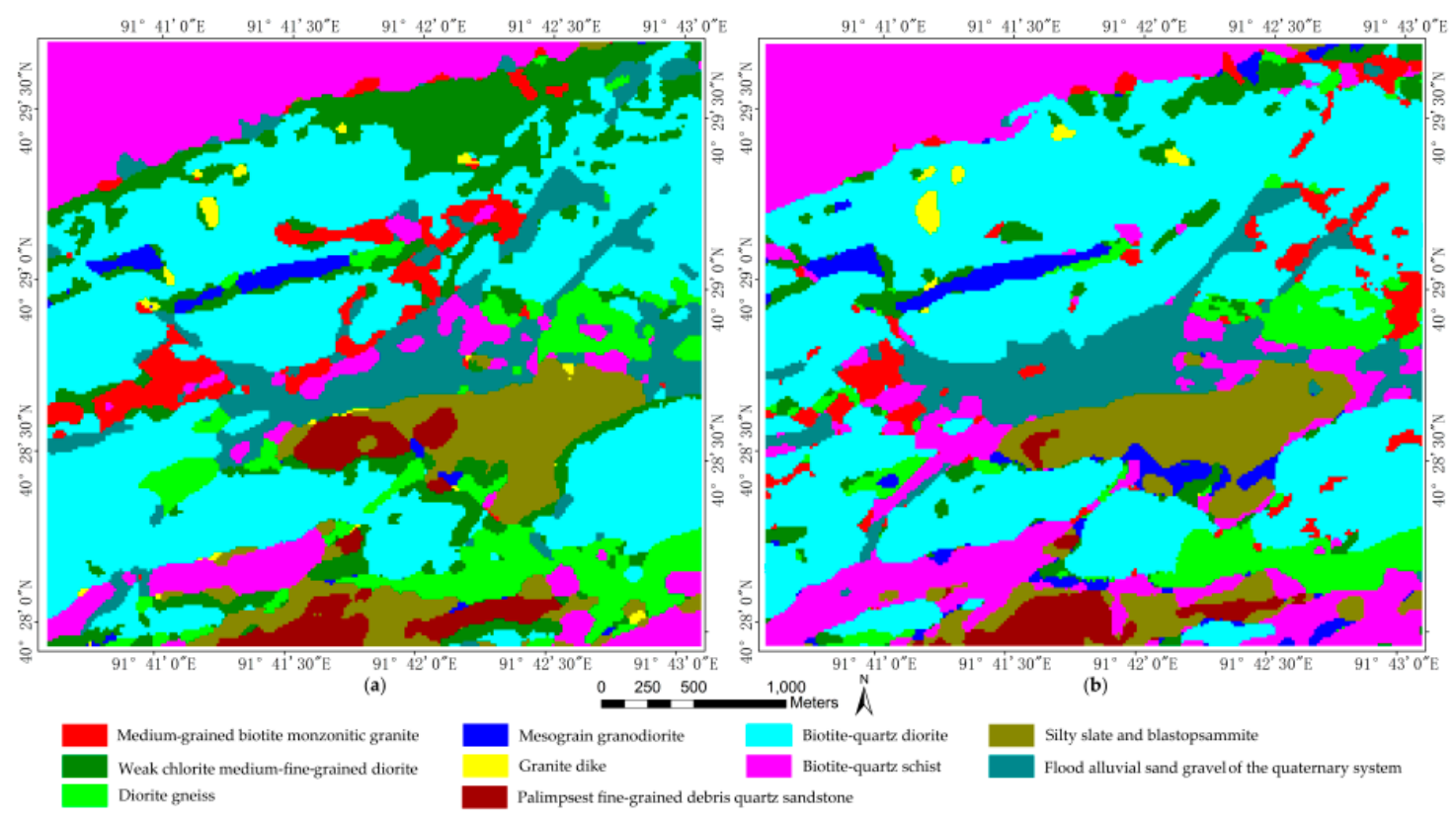

Figure 6. Lithological classification maps after the post-classification processing are shown. (a) The lithological classification map of ASTER data; and (b) the lithological classification map of OLI/Landsat-8 data.

Table 3. The statistical table of classification maps based on area percentages of various classes for WV-3, ASTER and OLI/Landsat-8 data.

\begin{tabular}{|c|c|c|c|c|}
\hline \multirow{2}{*}{$\begin{array}{l}\text { Category } \\
\text { Number }\end{array}$} & \multirow{2}{*}{ Category Name } & \multicolumn{3}{|c|}{ Area Percentages } \\
\hline & & WV-3 & ASTER & OLI/Landsat-8 \\
\hline 1 & Medium-grained biotite monzonitic granite & $2.93 \%$ & $4.17 \%$ & $3.93 \%$ \\
\hline 2 & Weak chlorite medium-fine-grained diorite & $9.76 \%$ & $9.65 \%$ & $4.39 \%$ \\
\hline 3 & Mesograin granodiorite & $3.75 \%$ & $2.19 \%$ & $2.94 \%$ \\
\hline 4 & Granite dike & $0.62 \%$ & $0.34 \%$ & $0.48 \%$ \\
\hline 5 & Biotite-quartz diorite & $41.66 \%$ & $41.45 \%$ & $43.58 \%$ \\
\hline 6 & Biotite-quartz schist & $14.83 \%$ & $14.82 \%$ & $20.23 \%$ \\
\hline 7 & Silty slate and blastopsammite & $6.79 \%$ & $8.07 \%$ & $8.14 \%$ \\
\hline 8 & Flood alluvial sand gravel & $8.60 \%$ & $9.59 \%$ & $8.03 \%$ \\
\hline 9 & Palimpsest fine-grained debris quartz sandstone & $3.53 \%$ & $3.40 \%$ & $2.19 \%$ \\
\hline 10 & Diorite gneiss & $7.51 \%$ & $6.33 \%$ & $6.08 \%$ \\
\hline
\end{tabular}




\subsection{Classification Accuracy}

The classification accuracy was quantitatively evaluated by test samples via a confusion matrix, and the kappa coefficient.

The overall accuracy of WorldView-3 data classification is $87 \%$ (810/927) and the kappa coefficient is 0.86 . Among them, seven classes' average accuracy was greater than $90 \%$ : diorite gneiss, palimpsest fine-grained debris quartz sandstone, flood alluvial sand gravel of the Quaternary system, silty slate and blastopsammite, biotite-quartz diorite, granite dike, and Mesograin granodiorite, respectively. Lithological units of lower classification precision were biotite-quartz schist and weak chlorite medium-fine-grained diorite. The overall accuracy of ASTER data classification is 70\% (648/927) and the kappa coefficient is 0.6648. It was flood alluvial sand gravel of the Quaternary system and medium-grained biotite monzonitic granite whose average accuracy is higher than, or equal to, $90 \%$, showing a perfect classification effect. Granite dike and weak chlorite medium-fine-grained diorite, as well as diorite gneiss, presented a poor classification result. The overall accuracy of OLI/Landsat-8 data classification is $74 \%(684 / 927)$ and kappa coefficient is 0.7076 . Flood alluvial sand gravel of the Quaternary system, silty slate and blastopsammite, and mesograin granodiorite attested higher veracity. On the contrary, the accuracy of diorite gneiss and weak chlorite medium-fine-grained diorite was low. The classification accuracy of all kinds of lithological units is shown in Table 4 .

Table 4. Each class' producer accuracy, user accuracy and average accuracy of WorldView-3, ASTER, and OLI/Landsat-8 data respectively (\%).

\begin{tabular}{cccccccccc}
\hline Data Type & \multicolumn{3}{c}{ WorldView-3 } & \multicolumn{3}{c}{ ASTER } & & \multicolumn{2}{c}{ OLI/Landsat-8 } \\
\hline $\begin{array}{c}\text { Category } \\
\text { Name }\end{array}$ & Prod.acc & User.acc & Average.acc & Prod.acc & User.acc & Average.acc & Prod.acc & User.acc & Average.acc \\
\hline 1 & 80.00 & 80.00 & 80.00 & 80.00 & 100.00 & 90.00 & 30.00 & 100.00 & 65.00 \\
2 & 60.00 & 66.67 & 63.34 & 30.00 & 27.27 & 28.64 & 40.00 & 66.67 & 53.34 \\
3 & 100.00 & 83.33 & 91.67 & 70.00 & 100.00 & 85.00 & 80.00 & 100.00 & 90.00 \\
4 & 90.00 & 100.00 & 95.00 & 40.00 & 66.67 & 53.34 & 40.00 & 80.00 & 60.00 \\
5 & 92.31 & 92.31 & 92.31 & 92.31 & 66.67 & 79.49 & 100.00 & 56.52 & 78.26 \\
6 & 60.00 & 75.00 & 67.50 & 80.00 & 88.89 & 84.45 & 100.00 & 71.43 & 85.72 \\
7 & 100.00 & 100.00 & 100.00 & 90.00 & 64.29 & 77.15 & 100.00 & 83.33 & 91.67 \\
8 & 100.00 & 90.91 & 95.46 & 90.00 & 100.00 & 95.00 & 100.00 & 90.91 & 95.46 \\
9 & 90.00 & 100.00 & 95.00 & 50.00 & 83.33 & 66.67 & 70.00 & 100.00 & 85.00 \\
10 & 100.00 & 83.33 & 91.67 & 70.00 & 46.67 & 58.34 & 70.00 & 50.00 & 60.00 \\
\hline
\end{tabular}

It is known from the above description that these three types of data were similar in the classification accuracy of flood alluvial sand gravel and mesograin granodiorite. The classification effect was large and stable and the classification accuracy and effect of WV-3 were better in five classes: diorite gneiss, palimpsest fine-grained debris quartz sandstone, silty slate and blastopsammite, biotite-quartz diorite, and granite dike, respectively. Meanwhile, biotite-quartz schist worked better with the ASTER data and OLI/Landsat-8 data classification; medium-grained biotite monzonitic granite used ASTER data for better classification. It is worth noting that the classification of the weak chlorite medium-fine-grained diorite was non-ideal using the above three kinds of remote sensing data.

\section{Discussion}

According to the classification results, the overall classification effect of the WV-3 image was significantly better than that of ASTER and OLI/landsat-8 images, which was undoubtedly due to its higher special and spatial resolution.

The spectral responses of lithological units are conditioned by several factors including atmospheric effects, the spectral and spatial resolution of the image, sub-pixel level heterogeneity in chemical and mineralogical composition of the rock, presence of soil, vegetation cover, and weathering. Thus, even for the same rock type, the actual spectra captured from remote sensing measurements can be significantly different from the laboratory spectra of the pure member, even after rigorous pre-processing [17]. However, the main diagnostic absorption features could be described, to varying 
degrees. The average spectral curve of each class could be obtained from the training samples (Figure 7).

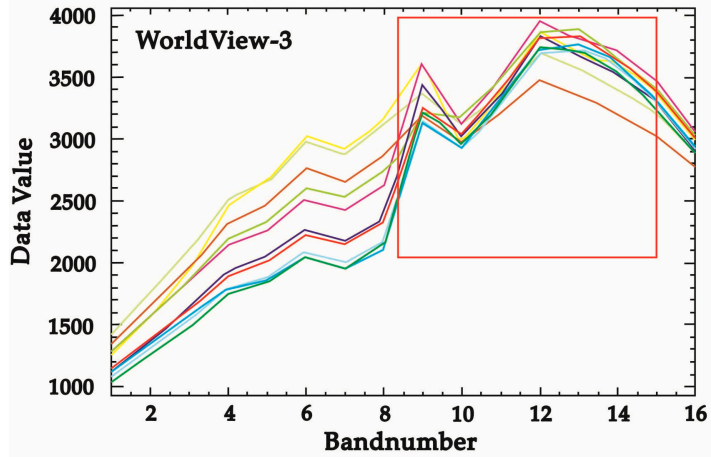

(a)

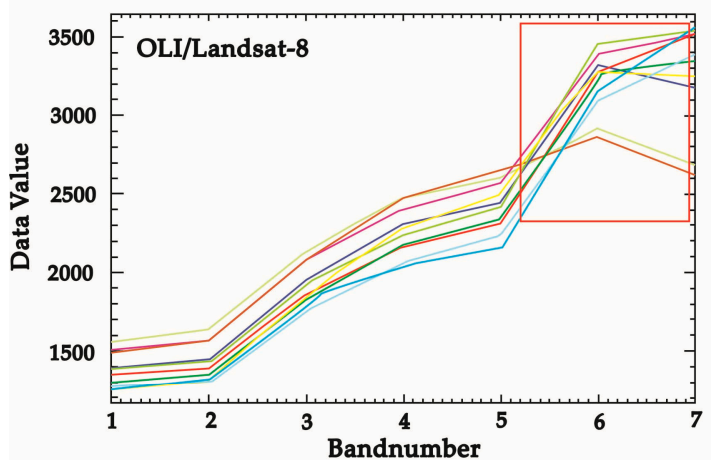

(c)

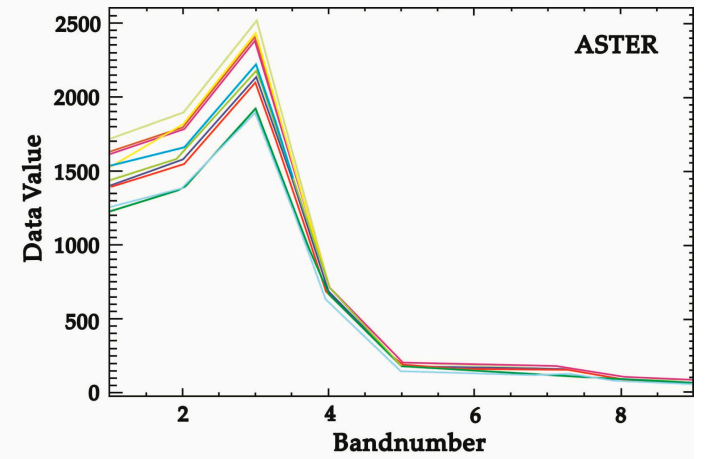

(b)

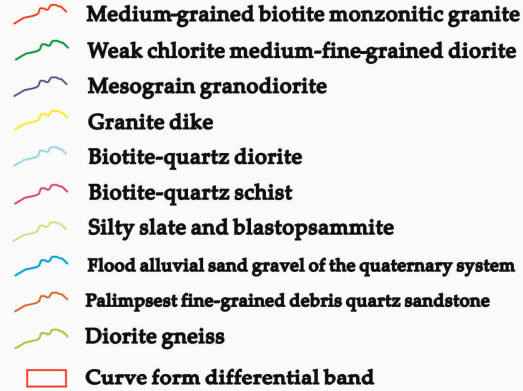

Figure 7. The average spectral curve of each class obtained from WorldView-3, ASTER, and OLI/landsat-8 data, respectively. (a) WorldView-3's average spectral curve; (b) ASTER's average spectral curve; and (c) OLI/Landsat-8's average spectral curve.

A large number of important rock-forming minerals do not display diagnostic absorption features at VNIR wavelengths, and spectral features in the VNIR spectral region are mainly caused by different physical processes [60]. It can be seen from Figure 7 that various lithological spectra curves, in VNIR wavelengths, had certain similarity, which indicates the consistency of geological evolutionary processes and regularity in a relatively small area. Obviously, most mineral absorption features were located in the SWIR wavelengths.

For this study area, various lithological spectrum curves, in bands 1-8 (visible to near-infrared wavelengths) and band 16 (SWIR8) of the WV-3 image were similar in shape, with different reflection intensities. In bands 9-15 (SWIR1-7), the shapes of the waveform curves were significantly different. Therefore, 16 bands of the WV-3 image reflected the intensity difference, as well as the spectral curve shape distinction, provided more classification criteria, especially the additional SWIR 1-7 bands, offered richer spectral curve information for classification.

In the bands 1-5 (visible to near-infrared wavelengths) of the OLI/landsat- 8 image, the differences of various lithological spectrum curves were reflected in the reflection intensity, while in the bands 6-7 (shortwave infrared wavelengths), there were marked distinctions in both reflection intensity and curve configuration. Thus, the classification accuracy could reach $74 \%$ when the spatial resolution was lower than the WV-3 image.

The classification accuracy of ASTER image was the lowest. In bands 1-3 (visible to near-infrared wavelengths), the reflection intensities of various lithological spectrum curves were disparate while, in bands 4-9 (SWIR 1-6), the spectral curves of all lithological units showed a decreasing trend. This was consistent with the patterns of WV-3's SWIR bands, and small but crucial curve 
morphological differences still existed in the SWIR bands, though they were not obvious in the Figure 7. Previous studies have shown that SVM algorithm could be applied to lithological mapping based on ASTER data $[11,15,51]$. There were three reasons for the low accuracy: first, the differences of the spectral curves of various lithological units in the study area were mainly reflected in the intensity; second, the radiation quantification level of ASTER image is 8-bit, which is lower than the radiation quantization level of WV-3 and OLI/landsat-8 images. Although it was unified to 16-bit during pre-processing, the ASTER data only could record relatively limited radiance brightness; third, the difference of data acquisition time between three kinds of data caused some errors. Additionally, the classification accuracy of ASTER data was lower than that of OLI/Landsat- 8 data, one of the important reasons is that OLI/Landsat- 8 data executed image fusion, including more detailed texture information.

Above all, in the application of three kinds of data, we found that although each sensor band setting was different, each class' lithological characters performed well in the shortwave infrared spectrum.

The accuracy of individual lithological unit is also an important aspect of assessing WV-3 data. For the accuracy of a single lithological class, most lithological units had higher classification accuracy in the WV-3 lithological map, or the accuracy of three kinds of data was slightly different. However, the classification accuracy of biotite-quartz schist in WV-3 image was significantly lower than that of ASTER and OLI/landsat-8 images, while the classification accuracy in ASTER and OLI/landsat-8 images were extremely similar. By observing lithological maps, the error mainly occurred in the southeast corner of the research area (Figure 8).

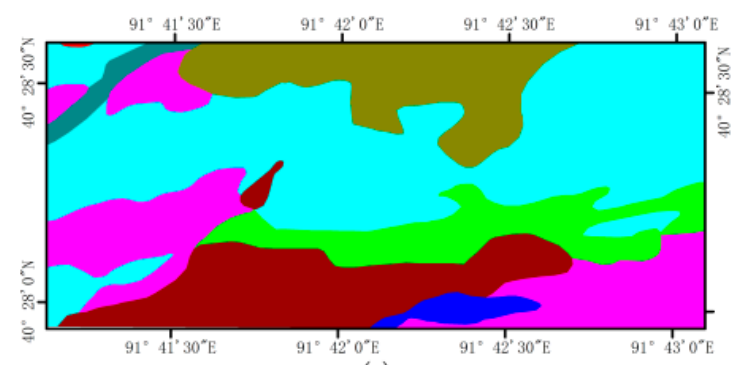

(a)

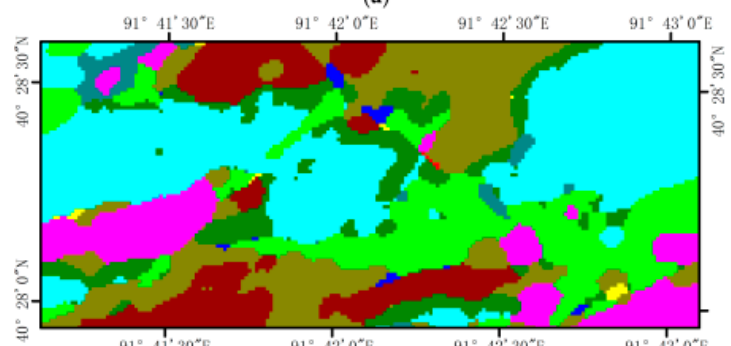

(c)

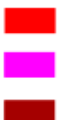

Medium-grained biotite monzonitic granite

Biotite-quartz schis

Palimpsest fine-grained debris quartz sandstone Silty slate and blastopsammite

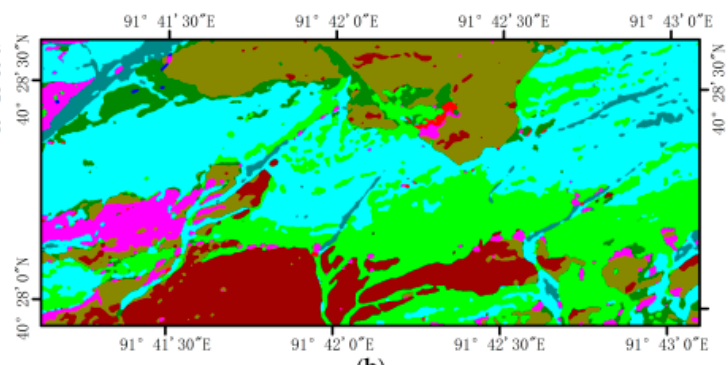

(b)

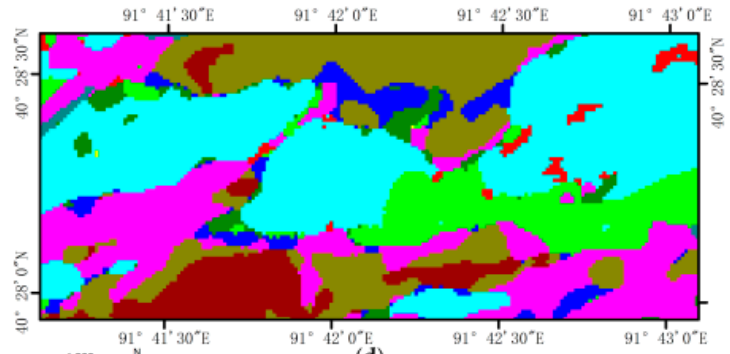

(d)

Mesograin granodiorite

Diorite gneiss

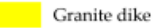

Weak chlorite medium-fine-grained diorite

Flood alluvial sand gravel of the quaternary system

Figure 8. Lithological classification maps in the southeast corner of the research area. (a) Lithological map by visual interpretation; (b) lithological classification map of WV-3 data; (c) lithological classification map of ASTER data; and (d) lithological classification map of OLI/Landsat data. Biotite-quartz schist was not recognized in the WV-3 data.

In the WV-3 lithological map, there was a certain amount of confusion between biotite-quartz schist and diorite gneiss. According to the detailed analysis, there are two reasons for the low classification accuracy: first, the diagnostic absorption features of the biotite-quartz schist were located in 2250-2400 nm range, with two pronounced emittance minimums (Figure 9). Only one emittance 
minimum, near $2250 \mathrm{~nm}$ located in the SWIR 7 band of the WV-3 data, and WV-3 SWIR bands are discontinuous, while the diagnostic absorption features were completely covered by ASTER's spectral range, because of the SWIR 6 band (centered at $2400 \mathrm{~nm}$ ). Additionally, there was a continuous SWIR band (centered at $2200 \mathrm{~nm}$ ) in OLI/Landsat- 8 data, which recorded more continuous change information of the diagnostic absorption features. When it went through weathering, the diagnostic absorption features were weakened distinctly; second, biotite-quartz schist and diorite gneiss were interleaved in terms of geographical position, which generated some mixed pixels.
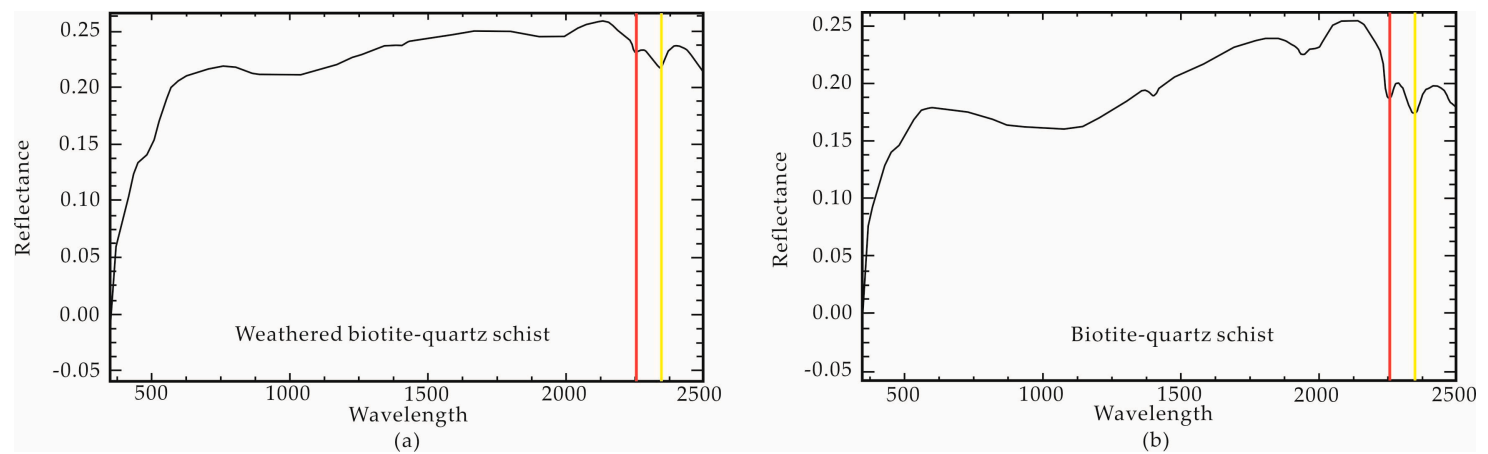

Figure 9. Spectral curve of weathered biotite-quartz schist and fresh biotite-quartz schist acquired by ASD Field spec-FRTM spectroradiometer in July 2015. There were two pronounced emittance minima marked by different colored lines. (a) Spectral curve of weathered biotite-quartz schist; and (b) spectral curve of fresh biotite-quartz schist.

Additionally, it could be discovered from Figure 8 that the distribution area of palimpsest fine-grained debris quartz sandstone in the WV-3 lithological map was similar to the lithological map by visual interpretation, but there was a mistake between palimpsest fine-grained debris quartz sandstone and silty slate blastopsammite in ASTER and OLI/Landsat-8 lithological maps. On the one hand, the diagnostic absorption features of palimpsest fine-grained debris quartz sandstone located near $1500 \mathrm{~nm}$ and $2200 \mathrm{~nm}$, which completely covered by SWIR 2 and SWIR 6 in the WV-3 data. Thus, the accuracy of the palimpsest fine-grained debris quartz sandstone in the WV-3 lithological map was high. On the other hand, it was the result of confusion between similar minerals at lower multispectral spectral resolution, as well as spectral mixing effects. There was some mistake between the mesograin granodiorite and biotite-quartz diorite due to the same reason.

Moreover, though the classification of the weak chlorite medium-fine-grained diorite was non-ideal by using three kinds of remote sensing data, the area of weak chlorite medium-fine-grained diorite in the WV-3 lithological map was much larger than that of visual interpretation lithological map, ASTER and OLI/Landsat- 8 lithological maps. In the added area were patchy speckles which had a banding distribution. It was not ruled out that due to its high spatial and spectral resolution, WV-3 data was more sensitive to this unit, which distributed dispersedly, but had some special diagnostic absorption features near $2200 \mathrm{~nm}$. Thus, the test samples caused some of the errors in accuracy, which were randomly selected according to the geologic map of the visual interpretation. The accuracy of diorite gneiss in the WV-3 lithological map was high. The above phenomenon illustrated WV-3's unique exploration ability for some metamorphic rocks or some rocks that undergo metamorphosis.

The classification accuracy of the granite dike in the WV-3 lithological classification map was significantly better than that of the other two kinds of data. Since the distribution area of the granite dike was small, the higher spatial resolution guaranteed higher classification accuracy. The WV-3 data contained more detail, as well.

The above part analyzes the advantages and disadvantages of WV-3 data from the perspective of spectral curve and classification accuracy of lithological units. And the sample set is also an important factor affecting the classification accuracy. Selecting the training samples via the lithological map of 
the visual interpretation had some uncertainty. Meanwhile, due to the different spatial resolution of the three kinds of data, the lithological boundary reflected by spectral data was also not consistent. Test samples were randomly selected, so the sample of the same geographic location may correspond to different classification results. Besides, there were inevitable errors due to the difference between data acquisitions, mainly caused by weathering and erosion process.

\section{Conclusions}

This paper executed lithological mapping using WV-3 data and an SVM model, and compared the lithological classification results of ASTER and OLI/Landsat 8 data for the first time. Spectral and spatial characteristics of the WV-3 data were assessed. The results showed that the classification accuracy of WV-3 data was 17\% higher than that of ASTER data, which was 14\% higher than that of OLI/Landsat 8 data, indicating that the WV-3 data had significant advantages in visual interpretation and supervised classification. The high spatial resolution of WV-3 data ensures the identification of the small rock mass. WV-3's additional SWIR bands have unique exploration ability, especially for some metamorphic rocks or some rocks that undergo metamorphosis. Additionally, SVM models are appropriate for WV-3 data.

However, despite this high accuracy of the WV-3 data, previous lithological mapping demonstrates that the statistical methods do not actually accurately map the known mineral distributions, mainly because they do not take into account the physical and mathematical models tied to spectral signatures and mineral mixing. Under the circumstances, more rigorous models need to be created for lithological mapping. We will conduct further research.

To sum up, WV-3 data sets a high spatial and spectral resolution as a whole, the additional SWIR bands have played a huge role in lithological mapping, and will greatly meet the needs of large-scale geological mapping work, even though this data is not applicable to all lithological units. And this article also provides a feasible approach to analyze the application potential of new data.

Acknowledgments: This work was supported by the "Iron and Manganese Resources Investigation Projection" from the Chinese Academy of Geological Sciences (grant no. 12120115037901) and "A Remote-Sensing Comprehensive Survey on Mineral Resources in the West Kunlun Metallogenic Belt" from China Geological Survey (grant no. 1212011120890). Regional geological material and ground survey data were provided by Professor Jinzhong Yang and Professor Bokun Yan, who work in China Aero Geophysical Survey and Remote Sensing Center (AGRS), and here we express our sincere thanks. Thanks to the three anonymous reviewers as well.

Author Contributions: Shufang Tian, Bei Ye, Jia Ge, and Yaqin Sun conceived and designed the experiment; Yaqin Sun conducted the image pre-processing and field work; Bei Ye did lithological mapping experiment and analyzed the results; Shufang Tian, Jia Ge, Yaqin Sun, revised the paper; and Bei Ye wrote the paper.

Conflicts of Interest: The authors declare no conflict of interest.

\section{References}

1. Amer, R.; Kusky, T.; Ghulam, A. Lithological mapping in the central eastern desert of Egypt using ASTER data. J. Afr. Earth Sci. 2010, 56, 75-82. [CrossRef]

2. Haselwimmer, C.E.; Riley, T.R.; Liu, J.G. Lithologic mapping in the Oscar ii Coast area, Graham Land, Antarctic Peninsula using ASTER data. Int. J. Remote Sens. 2011, 32, 2013-2035. [CrossRef]

3. Sadeghi, B.; Khalajmasoumi, M.; Afzal, P.; Moarefvand, P.; Yasrebi, A.B.; Wetherelt, A.; Foster, P.; Ziazarifi, A. Using ETM+ and ASTER sensors to identify iron occurrences in the Esfordi 1:100,000 mapping sheet of central Iran. J. Afr. Earth Sci 2013, 85, 103-114. [CrossRef]

4. Tangestani, M.H.; Jaffari, L.; Vincent, R.K.; Sridhar, B.B.M. Spectral characterization and ASTER-based lithological mapping of an ophiolite complex: A case study from Neyriz Ophiolite, SW Iran. Remote Sens. Environ. 2011, 115, 2243-2254. [CrossRef]

5. Zhang, X.; Pazner, M. Comparison of lithologic mapping with ASTER, Hyperion, and ETM data in the southeastern chocolate mountains, USA. Photogramm. Eng. Remote Sens. 2007, 73, 555-561. [CrossRef] 
6. Madani, A.A.; Emam, A.A. SWIR ASTER band ratios for lithological mapping and mineral exploration: A case study from EL Hudi area, southeastern desert, Egypt. Arab. J. Geosci. 2009, 4, 45-52. [CrossRef]

7. Mars, J.C.; Rowan, L.C. Spectral assessment of new ASTER SWIR surface reflectance data products for spectroscopic mapping of rocks and minerals. Remote Sens. Environ. 2010, 114, 2011-2025. [CrossRef]

8. Amri, K.; Mahdjoub, Y.; Guergour, L. Use of Landsat 7 ETM+ for lithological and structural mapping of Wadi Afara Heouine area (Tahifet-Central Hoggar, Algeria). Arab. J. Geosci. 2010, 4, 1273-1287. [CrossRef]

9. He, J.; Harris, J.R.; Sawada, M.; Behnia, P. A comparison of classification algorithms using Landsat-7 and Landsat-8 data for mapping lithology in Canada's Arctic. Int. J. Remote Sens. 2015, 36, 2252-2276. [CrossRef]

10. Amri, K.; Rabai, G.; Benbakhti, I.M.; Khennouche, M.N. Mapping geology in Djelfa district (Saharan Atlas, Algeria), using Landsat 7 ETM+ data: An alternative method to discern lithology and structural elements. Arab. J. Geosci. 2017, 10, 87. [CrossRef]

11. Masoumi, F.; Eslamkish, T.; Abkar, A.A.; Honarmand, M.; Harris, J.R. Integration of spectral, thermal, and textural features of ASTER data using random forests classification for lithological mapping. J. Afr. Earth Sci. 2017, 129, 445-457. [CrossRef]

12. Cao, G.; Li, Y.; Liu, Y.; Shang, Y. Automatic change detection in high-resolution remote-sensing images by means of level set evolution and support vector machine classification. Int. J. Remote Sens. 2014, 35, 6255-6270. [CrossRef]

13. Deng, C.; Pan, H.; Fang, S.; Konaté, A.A.; Qin, R. Support vector machine as an alternative method for lithology classification of crystalline rocks. J. Geophys. Eng. 2017, 14, 341-349. [CrossRef]

14. Larar, A.M.; Chauhan, P.; Suzuki, M.; Wang, J.; Parakh, K.; Thakur, S.; Chudasama, B.; Tirodkar, S.; Porwal, A.; Bhattacharya, A. Machine learning and spectral techniques for lithological classification. Proc. SPIE 2016, 9880, 98801Z.

15. Othman, A.; Gloaguen, R. Improving lithological mapping by SVM classification of spectral and morphological features: The discovery of a new chromite body in the mawat ophiolite complex (Kurdistan, NE Iraq). Remote Sens. 2014, 6, 6867-6896. [CrossRef]

16. Seifi Majdar, R.; Ghassemian, H. A probabilistic SVM approach for hyperspectral image classification using spectral and texture features. Int. J. Remote Sens. 2017, 38, 4265-4284. [CrossRef]

17. Yu, L.; Porwal, A.; Holden, E.-J.; Dentith, M.C. Towards automatic lithological classification from remote sensing data using support vector machines. Comput. Geosci. 2012, 45, 229-239. [CrossRef]

18. Zhou, J.J.; Tian, S.F.; Wang, N.; Hu, X. Enhancement and application of Worldview-2 to geological interpretation. Adv. Mater. Res. 2014, 1010-1012, 1237-1242. [CrossRef]

19. Adiri, Z.; Harti, A.E.; Jellouli, A.; Maacha, L.; Bachaoui, E.M. Lithological mapping using Landsat 8 OLI and TERRA ASTER multispectral data in the Bas Drâa Inlier, Moroccan Anti Atlas. J. Appl. Remote Sens. 2016, 10, 016005. [CrossRef]

20. Eslami, A.; Ghaderi, M.; Rajendran, S.; Pour, A.B.; Hashim, M. Integration of ASTER and Landsat TM remote sensing data for chromite prospecting and lithological mapping in Neyriz ophiolite zone, South Iran. Resour. Geol. 2015, 65, 375-388. [CrossRef]

21. Pournamdari, M.; Hashim, M.; Pour, A.B. Spectral transformation of ASTER and Landsat TM bands for lithological mapping of Soghan ophiolite complex, south Iran. Adv. Space Res. 2014, 54, 694-709. [CrossRef]

22. Vanderhoof, M.; Distler, H.; Mendiola, D.; Lang, M. Integrating Radarsat-2, LiDAR, and Worldview-3 imagery to maximize detection of forested inundation extent in the Delmarva Peninsula, USA. Remote Sens. 2017, 9, 105. [CrossRef]

23. Black, M.; Riley, T.R.; Ferrier, G.; Fleming, A.H.; Fretwell, P.T. Automated lithological mapping using airborne hyperspectral thermal infrared data: A case study from Anchorage Island, Antarctica. Remote Sens. Environ. 2016, 176, 225-241. [CrossRef]

24. Deroin, J.-P.; Djemai, S.; Bendaoud, A.; Brahmi, B.; Ouzegane, K.; Kienast, J.-R. Integrating geologic and satellite radar data for mapping dome-and-basin patterns in the in Ouzzal Terrane, Western Hoggar, Algeria. J. Afr. Earth Sci. 2014, 99, 652-665. [CrossRef]

25. Pour, A.B.; Hashim, M. Structural geology mapping using PALSAR data in the Bau gold mining district, Sarawak, Malaysia. Adv. Space Res. 2014, 54, 644-654. [CrossRef]

26. Pour, A.B.; Hashim, M. Application of PALSAR-2 remote sensing data for structural geology and topographic mapping in Kelantan river basin, Malaysia. IOP Conf. Ser. Earth Environ. Sci. 2016, 37, 012067. [CrossRef] 
27. Grebby, S.; Cunningham, D.; Naden, J.; Tansey, K. Lithological mapping of the Troodos ophiolite, Cyprus, using airborne LIDAR topographic data. Remote Sens. Environ. 2010, 114, 713-724. [CrossRef]

28. Kruse, F.; Perry, S. Mineral mapping using simulated Worldview-3 short-wave-infrared imagery. Remote Sens. 2013, 5, 2688-2703. [CrossRef]

29. Asadzadeh, S.; de Souza Filho, C.R. Investigating the capability of Worldview-3 superspectral data for direct hydrocarbon detection. Remote Sens. Environ. 2016, 173, 162-173. [CrossRef]

30. Sun, Y.; Tian, S.; Di, B. Extracting mineral alteration information using Worldview-3 data. Geosci. Front. 2017, 8, 1051-1062. [CrossRef]

31. Barazzetti, L.; Roncoroni, F.; Brumana, R.; Previtali, M. Georeferencing accuracy analysis of a single Worldview-3 image collected over Milan. ISPRS Int. Arch. Photogramm. Remote Sens. Spat. Inf. Sci. 2016, XLI-B1, 429-434. [CrossRef]

32. Hu, F.; Gao, X.M.; Li, G.Y.; Li, M. Dem extraction from Worldview-3 stereo-images and accuracy evaluation. ISPRS Int. Arch. Photogramm. Remote Sens. Spat. Inf. Sci. 2016, XLI-B1, 327-332. [CrossRef]

33. Li, D.; Ke, Y.; Gong, H.; Li, X. Object-based urban tree species classification using bi-temporal Worldview-2 and Worldview-3 images. Remote Sens. 2015, 7, 16917-16937. [CrossRef]

34. Sibanda, M.; Mutanga, O.; Rouget, M. Testing the capabilities of the new Worldview-3 space-borne sensor's red-edge spectral band in discriminating and mapping complex grassland management treatments. Int. J. Remote Sens. 2016, 38, 1-22. [CrossRef]

35. Warner, T.A.; Skowronski, N.S.; Gallagher, M.R. High spatial resolution burn severity mapping of the new jersey pine barrens with Worldview-3 near-infrared and shortwave infrared imagery. Int. J. Remote Sens. 2016, 38, 598-616. [CrossRef]

36. Niroumand-Jadidi, M.; Vitti, A. Optimal band ratio analysis of Worldview-3 imagery for bathymetry of shallow rivers (case study: Sarca river, Italy). ISPRS Int. Arch. Photogramm. Remote Sens. Spat. Inf. Sci. 2016, XLI-B8, 361-364. [CrossRef]

37. Wang, T.; Zhang, H.; Lin, H.; Fang, C. Textural-spectral feature-based species classification of mangroves in Mai Po nature reserve from Worldview-3 imagery. Remote Sens. 2016, 8, 24. [CrossRef]

38. Zheng, Y.-F.; Xiao, W.-J.; Zhao, G. Introduction to tectonics of China. Gondwana Res. 2013, 23, 1189-1206. [CrossRef]

39. Su, B.-X.; Qin, K.-Z.; Sakyi, P.A.; Liu, P.-P.; Tang, D.-M.; Malaviarachchi, S.P.K.; Xiao, Q.-H.; Sun, H.; Dai, Y.-C.; Yan, H. Geochemistry and geochronology of acidic rocks in the Beishan region, NW China: Petrogenesis and tectonic implications. J. Asian Earth Sci. 2011, 41, 31-43. [CrossRef]

40. Worldview-3 Satellite Sensor. Available online: https://www.satimagingcorp.com/satellite-sensors/ worldview-3/ (accessed on 12 September 2017).

41. Digital Globe. Available online: https://content.satimagingcorp.com.s3.amazonaws.com/static/satellitesensor-specification/WorldView-3-PDF-Download.pdf (accessed on 12 September 2017).

42. Nguyen, H.C.; Jung, J.; Lee, J.; Choi, S.U.; Hong, S.Y.; Heo, J. Optimal atmospheric correction for above-ground forest biomass estimation with the ETM+ remote sensor. Sensors 2015, 15, 18865-18886. [CrossRef] [PubMed]

43. Schäfer, K.; Perkins, T.; Comerón, A.; Adler-Golden, S.; Matthew, M.; Slusser, J.R.; Picard, R.H.; Berk, A.; Anderson, G.; Carleer, M.R.; et al. Retrieval of atmospheric properties from hyper and multispectral imagery with the FLAASH atmospheric correction algorithm. Proc. SPIE 2005, 5979, 59790E.

44. Rani, N.; Mandla, V.R.; Singh, T. Evaluation of atmospheric corrections on hyperspectral data with special reference to mineral mapping. Geosci. Front. 2017, 8, 797-808. [CrossRef]

45. Iwasaki, A.; Tonooka, H. Validation of a crosstalk correnction algorithm for ASTER/SWIR. IEEE Trans. Geosci. Remote Sens. 2005, 12, 2747-2751. [CrossRef]

46. Gasmi, A.; Gomez, C.; Zouari, H.; Masse, A.; Ducrot, D. PCA and SVM as geo-computational methods for geological mapping in the southern of Tunisia, using ASTER remote sensing data set. Arab. J. Geosci. 2016, 9, 753. [CrossRef]

47. Zhou, Q.; Zhang, J.; Tian, Q.; Zhuo, L.; Geng, W. Automatic endmember extraction using pixel purity index for hyperspectral imagery. In Proceedings of the International Conference on Multimedia Modeling, Miami, FL, USA, 4-6 January 2016; Volume 9517, pp. 207-217.

48. Ghosh, G.; Kumar, S.; Saha, S.K. Hyperspectral satellite data in mapping salt-affected soils using linear spectral unmixing analysis. J. Indian Soc. Remote Sens. 2011, 40, 129-136. [CrossRef] 
49. Support Vector Machine. Available online: https://en.wikipedia.org/wiki/Support_vector_machine (accessed on 12 September 2017).

50. Burges, C. A tutorial on support vector machines for pattern recognition. Data Min. Knowl. Discov. 1998, 2, 121-167. [CrossRef]

51. Othman, A.A.; Gloaguen, R. Integration of spectral, spatial and morphometric data into lithological mapping: A comparison of different machine learning algorithms in the Kurdistan region, NE Iraq. J. Asian Earth Sci. 2017, 146, 90-102. [CrossRef]

52. Sahoo, S.; Jha, M.K. Pattern recognition in lithology classification: Modeling using neural networks, self-organizing maps and genetic algorithms. Hydrogeol. J. 2016, 25, 311-330. [CrossRef]

53. Yang, X. Parameterizing support vector machines for land cover classification. Photogramm. Eng. Remote Sens. 2011, 77, 27-37. [CrossRef]

54. Liu, P.; Choo, K.-K.R.; Wang, L.; Huang, F. SVM or deep learning? A comparative study on remote sensing image classification. Soft Comput. 2017, 21, 7053-7065. [CrossRef]

55. Wang, M.; Wan, Y.; Ye, Z.; Lai, X. Remote sensing image classification based on the optimal support vector machine and modified binary coded ant colony optimization algorithm. Inf. Sci. 2017, 402, 50-68. [CrossRef]

56. Congalton, R.G. A review of assessing the accuracy of remotely sensed data. Remote Sens. Environ. 1991, 37, 35-46. [CrossRef]

57. Grebby, S.; Naden, J.; Cunningham, D.; Tansey, K. Integrating airborne multispectral imagery and airborne LiDAR data for enhanced lithological mapping in vegetated terrain. Remote Sens. Environ. 2011, 115, $214-226$. [CrossRef]

58. Brown, D.G.; Lusch, D.P.; Duda, K.A. Supervised classification of types of glaciated landscapes using digital elevation data. Geomorphology 1998, 21, 233-250. [CrossRef]

59. Monserud, R.A.; Leemans, R. Comparing global vegetation maps with the kappa statistic. Ecol. Model. 1992, 62, 275-293. [CrossRef]

60. Clark, R.N.; Swayze, G.A.; Livo, K.E.; Kokaly, R.F.; Sutley, S.J.; Dalton, J.B.; McDougal, R.R.; Gent, C.A. Imaging spectroscopy: Earth and planetary remote sensing with the USGS tetracorder and expert systems. J. Geophys. Res. Planets 2003, 108. [CrossRef]

(C) 2017 by the authors. Licensee MDPI, Basel, Switzerland. This article is an open access article distributed under the terms and conditions of the Creative Commons Attribution (CC BY) license (http:/ / creativecommons.org/licenses/by/4.0/). 